\title{
ИДЕНТИФИКАЦИЯ ПОТЕНЦИАЛЬНЫХ БЕЛКОВ-МИШЕНЕЙ ОРГАНИЗМА ЧЕЛОВЕКА ДЛЯ ОПТИМИЗАЦИИ ТЕРАПИИ ВИЧ-ИНФЕКЦИИ НА ОСНОВЕ ИНТЕЛЛЕКТУАЛЬНОГО АНАЛИЗА ТЕКСТОВ
}

\author{
Н.Ю. Бизюкова, О.А. Тарасова, В.В. Поройков \\ Лаборатория структурно-функционального конструирования лекарств, отдел \\ биоинформатики, ФГБНУ «НИИ биомедицинской химии имени В.Н. Ореховича», \\ 119121, Россия, г. Москва, ул. Погодинская, д. 10, стр. 7.
}

DOI: 10.19163/MedChemRussia2021-2021-179

E-mail:nad.smol@gmail.com

Целью данной работы является извлечение наименований белков и генов организма, которые потенциально ассоциированы с различной скоростью прогрессии ВИЧ-инфекции, из текстов научных публикаций.

Для этого нами был разработан алгоритм распознавания наименований белков и генов в текстах научных публикаций с использованием скриптов (Python 3.7) и метода машинного обучения «условные случайные поля» (CRF). При пятикратной кросс-валидации на выборке объемом 2500 рефератов, были получены значения точности precision, recall и F1-score, равные 0,87, 0,81 и 0,84, соответственно.

Извлечение наименований белков и генов, потенциально ассоциированных с различной скоростью прогрессии ВИЧ-инфекции, проводилось из текстов рефератов, релевантных исследованиям об элитных контроллерах и типичных прогрессоров. Отбор публикаций проводился на основе алгоритма, реализованного на языке Python. Классификация рефератов по принадлежности к тематике элитных контроллеров и типичных прогрессоров проводилась с использованием машинного обучения с применением выборки текстов, отобранных вручную.

Из выборок текстов по элитным контроллерам и типичным прогрессорам были извлечены все наименования белков и генов с помощью разработанного алгоритма. Фильтрация извлеченных наименований белков и генов с точки зрения принадлежности к организму проводилась с использованием базы знаний UniProt и скрипта Python. Помимо фильтрации, данные из UniProt использовались для установления функции извлеченных белков и генов.

Окончательный список извлеченных уникальных наименований белков и генов, которые могут быть связаны с более медленной скоростью развития ВИЧ-инфекции состоял из 403 наименований. Белки и гены были верифицированы в литературе, и определена их функциональная значимость для более медленной прогрессии ВИЧ-инфекции у элитных контроллеров.

Работа выполнена при поддержке гранта РНФ 19-75-10097.

$$
-179-
$$

